\title{
PENDAMPINGAN PEMBELAJARAN BAHASA INGGRIS DASAR PADA SANTRI PONDOK PESANTREN NURUL HUDA(PPNH) SUKARAJA
}

\author{
Eka Warohma, ${ }^{1}$ M. Ilham Abdillah, ${ }^{2}$ Siti Mei Arini ${ }^{3}$ \\ Sekolah Tinggi Keguruan dan Ilmu Pendidikan (STKIP) Nurul Huda OKU Timur \\ 11ekawarohmah@gmail.com, 2milhamabdillah08@gmail.com, ${ }^{3}$ sitimeiarini@gmail.com.
}

Submitted: 2021-01-21 | Revised: 2021-05-31 | Accepted: 2021-06-02

\begin{abstract}
This English learning assistance starts at the beginning of the year at the beginning of the 2020/2021 school year. The target of this activity is the students of Madrassah Tsanawiyyah and Aliyyah, to be precise, the PPNH Central Girls Dormitory. This activity was carried out to balance learning in Islamic boarding school which used to fokus on the religius side, so that students not only explore religious knowledge such as English, thus activity has been carried out for 4 and a half months, the material provided isbasic material, including grammar, vocabukary and conversation. This activity received a good response from the students, even thei enthusiasm was quite large. This indicated that there is a desire the tjem to learn English.
\end{abstract}

Keywords: Community Services, English, Islamic Boarding School, Student

Abstrak. Pendampingan pembelajaran bahasa Inggris ini dimulai pada awal tahun ajaran 2020/2021 dan yang menjadi sasaran kegiatan ini adalah santriwati asrama putri pusat pondok pesantren Nurul Huda Sukaraja yang mana juga merupakan peserta didik di Madrasah Tsanawiyah dan Madrasah Aliyah. Kegiatan ini dilakukan guna memberikan wawasan bahasa Inggris kepada peserta didik yang mana pembelajaran di pondok pesantren yang sebelumnya belum pernah memberikan pembelajaran bahasa Inggris secara intensif, sehingga santri tak hanya mendapat ilmu agama tetapi juga mendapatkan bekal pengetahuan berbahasa Inggris saat mereka yang berguna setelah mereka lulus nanti. Kegiatan ini telah dilakukan selama empat setengah bulan dengan memberikan materi-materi dasar bahasa Inggris yang meliputi grammar, vocabullary, dan conversation. Kegiatan ini mendapatkan sambutan yang baik dari para santri. Hal ini menunjukan bahwa mereka tertarik untuk belajar bahasa Inggris

Kata Kunci: Pengabdian masyarakat, Bahasa Inggris, Santri 


\section{Pendahuluan}

Pesantren dan pendidikan merupakan satu dan lain hal yang saling terkait satu sama lain. ${ }^{1}$ Tentu saja hal ini melibatkan beberapa hal tercakup didalamnya. Sehingga dalam pembelajaran di pondok pesantren saat ini tidak terlepas dari lingkup sosial. Bahkan pada beberapa pondok pesantren juga dilaukan pembelajaran yang memang sesuai untuk era seperti ini untuk saat ini ada hal yang memang harus dikuasai banyak oleh semua golongan, yakni bahasa Inggris yang mana sudah tak asing lagi bagi kita. Bahasa Inggris merupakan bahasa asing pertama yang harus dikuasai oleh masyarakat. ${ }^{2}$

Pesantren memiliki fungsi yang penting dalam tatanan masyarakat, yakni sebagai lembaga pendidikan masyarakat guna membentuk sumber daya manusia yang dapat berperilaku dan paham akan nilai-nilai agama.

Pesantren sebagai lembaga pendidikan Islam mengalami perkembangan bentuk sesuai dengan perubahan zaman serta adanya dampak kemajuan ilmu pengetahuan dan tekhnologi. Akan tetapi, pondok pesantren tetap merupakan lembaga pendidikan agama Islam yang tumbuh dan berkembang dari masyarakat untuk masyarakat.

Yayasan Pondok Pesantren Nurul Huda (PPNH) adalah salah satu pondok terbesar di sumatera selatan. Pesantren ini merupakan pondok salafi yang berbasis modern. Pondok yang terletak diujung sumatera bagian selatan ini terdiri dari bebrapa unit asrama, yakni asrama Putri pusat 1 dan 2, asrama putra pusat, asrama el Umamy, asrama TPQ, PPNH2 dan masih dalam proses pebangunan PPNH 3 dan 4. Dalam pesantren ini lembaga pendidikan dimulai dari Taman Kanak-kanak hingga perguruan tinggi.

Lembaga ini selalu ingin mengikuti perkembangan zaman dan melakukan adaptasi dan akselerasi. Terbukti dimana pondok ini adalah salafy yang berbasis modern meskipun bukan bahasa asli dan terkesan sulit tetapi sudah sepatutnya untuk mempelajarinya agar tak ketinggalan zaman. Sebagaimana yang kita ketahui bahasa Inggris merupakan bahasa Internasional sehingga menjadi bahasa yang paling banyak digunakan di seluruh dunia. ${ }^{3}$ Maka, tentu saja perlu bagi kita untuk mendalaminya agar tidak ketinggalan zaman, selain itu juga Bahasa Inggris saat ini adalah bahasa internasional yang merupakan media komunikasi internasional yang paling luas. ${ }^{4}$ Bahasa Inggris saat ini sangat umum dipelajari dan digunakan. Akan tetapi belajar bahasa

\footnotetext{
${ }^{1}$ Agustina, E., Rohmah, A., \& Kuspiyah, H. (2019). Pendampingan Bimbingan Belajar Bahasa Inggris dan Bakti Sosial di Yayasan Pendidikan dan Sosial Roudlotut Thullab. Jurnal Indonesia Mengabdi, 1(1), 1-5.

2 Budiarti, Any.2013. Interferensi Babasa Indonesia ke dalam Bahasa Inggris pada Abstrak Jurnal Imiah.Bahasa dan Seni. (41, 1, 10-11).

${ }^{3}$ Hardjono Rayner. Kamus Saku Istilab Bahasa Asing. Jakarta : Gramedia Pustaka Utama, 2007.h. 25

4 Brumfit (2001:35). http://cuhyethun.blogspot.co.id/2015/08/hakikat-bahasainggris.html?=1
} 
inggris bukanlah hal yang mudah, dalam belajar bahasa Inggris sangat penting untuk memiliki kemauan dan ketekunan.

"Language is patterned system of arbitrary sound signals, characterized by structure dependence, creativity, displacement, duality, and cultural transmission". bahasa merupakan sistem yang terbentuk dari isyarat suara yang telah disepakati, yang ditandai dengan struktur yang saling tergantung, kreatifitas, penempatan, dualitas dan penyebaran budaya. ${ }^{5}$ Belajar bahasa Inggris akan lebih mudah jika lingkungan mendukung, membuat kita lebih cepat menguasai bahasa Inggris. Bacharudin Mustafa menyatakan bahwa anak yang menguasai bahasa asing memiliki kelebihan dalam hal intelektual yang fleksibel, ketrampilan akademik, berbahasa dan sosial. Selain itu, anak akan memiliki kesiapan memasuki suatu konteks pergaulan dengan berbagai bahasa dan budaya. Sehingga ketika dewasa anak akan menjadi sumber daya manusia yang berkualitas dan berprestasi. ${ }^{6}$

Begitu pula jika kita ingin lebih efektif dalam mengajar bahasa Inggris maka kita harus menjadikan bahasa Inggris sebagai bagian dari kehidupan kita. Itu artinya kita harus mencoba menggunakannya setiap hari jika memungkinkan. Untuk itu kita bisa membaca, mendengarkan, atau berbicara dalam bahasa Inggris di setiap kesempatan yang kita temui atau yang bisa kita buat. Atau dengan kata lain kita harus memprakktikan bahasa Inggris secara disiplin. Praktik adalah pembelajaran yang digunakan dengan tujuan melatih serta meningkatkan kemampuan peserta didik dalam menerapkan pengetahuan dan keterampilan yang telah diperoleh untuk dilakukan di kehidupan nyata atau lapangan, pekerjaan, atau tugas yang sebenarnya.

Namun demikian, masalah yang saat ini melanda masyarakat yang ingin belajar bahasa Inggris yaitu kemalasan. Untuk alasan apapun, bahasa Inggris masih dianggap sebagai bahasa yang sulit untuk dipahami dan dipelajari bagi kebanyakan orang. Karena itu, jika anda ingin mahir berbahasa Inggris maka mulai sekarang anda harus belajar. Anda hanya perlu mengetahui cara belajar yang benar agar lebih mudah bagi anda untuk memahaminya dengan cepat. Karena sesuatu yang dilakukan secara rutin dan terus menerus agar menjadi kebiasaan. ${ }^{8}$

Pondok Pesantren Nurul Huda adalah salah satu Pondok Pesantren besar di Sumatera Selatan. Pondok ini terdiri dari beberapa unit asrama di beberapa wilayah, dan berpusat di Desa Sukaraja Kecamatan Buay Madang, Kabupaten OKU Timur. Yayasan Pondok Pesantren Nurul Huda selain sebagai forum pendidikan pesantren juga dilengkapi dengan pendidikan berbasis kurikulum mulai dari jenjang RA hingga Perguruan Tinggi dan dalam proses program Pascasarjana.

\footnotetext{
5 Aitchison, Jean. 2008. Linguistics. London: Hodder Headline.h. 14

6 Bacharudin Mustafa, Pendidikan Usia Dini, (Bandung: Unpublished, Book. 2007), h. 34

7 Nana Sudjana. 2005. Dasar-dasar proses Belajar Mengajar. Bandung: Sina Baru Algesindo ., h.157-158.

8 Mulyasa 2012. Manajemen Pendidikan Karakter. Jakarta : Bumi Aksara., h.166
} 
Pada pendidikan asrama khususnya di pusat di desa Sukaraja pembelajaran bahasa Inggris masih sangat umum untuk pendidikan di asrama, bahkan bisa dikatakan tidak ada, para santri bahasa belajar Inggris hanya dalam lingkup sekolah. Dulu di asrama mereka hanya belajar ilmu agama, kini dilakukan upaya untuk menyeimbangkan ilmu yang di berikan kepada santri antara ilmu agama dengan ilmu umum seperti bahasa Inggris untuk meminimalisir keterbelakangan santri dalam bidang bahasa asing. Terlebih lagi bahasa Inggris merupakan bahasa internasional, sehingga akan dapat memperluas pengetahuan santri mengenai kehidupan dunia. Selain itu, bahasa dalam ranah ilmu pengetahuan bertujuan untuk mempercepat perkembangan ilmu pengetahuan itu.' Maka perlulah untuk dipelajari oleh setiap kalangan. Sebagaimana dijelaskan Dari Anas ra.

Rasulullab Saw. telah bersabda, "Bukanlah yang terbaik diantara kamu orang yang meninggalkan urusan dunia karena mengejar urusan akhirat, dan bukan pula orang yang terbaik orang yang meninggalkan akbiratnya karena mengejar urusan dunianya, sehingga ia memperoleh kedua-duanya, karena dunia itu adalah perantara yang menyampaikan ke akhirat, dan janganlah kamu menjadi beban orang lain."

Hadist di atas menjelaskan tentang kehidupan manusia yang seharusnya, yaitu kehidupan yang berimbang, kehidupan dunia harus diperhatikan disamping kehidupan di akhirat. Islam tidak memandang baik terhadap orang yang hanya mengutamakan urusan dunia saja, tapi urusan akhirat dilupakan. Sebaliknya Islam juga tidak mengajarkan umat manusia untuk konsentrasi hanya pada urusan akhirat saja sehingga melupakan kehidupan dunia. Disini cukup jelas bahwasanya belajar bahasa inggris merupakan hal patut dipelajari di lingkup pesantren.

\section{Hasil dan Pembahasan}

Kegiatan pendampingan Ini mendapat sambutan yang positif baik dari pihak asrama, yang mana kegiatan ini merupakan salah satu hal yang dibutuhkan santri untuk menunjang kemampuan mereka yang nantinya akan terjun ke masyarakat. Kegiatan pendampingan belajar bahasa Inggris ini merupakan suatu hal yang baru bagi santriwati. Yang sebelumnya kegiatan mereka seusai shalat subuh adalah mengaji, maka santriwati mempunyai jadwal tersendiri di setiap minggunya untuk bahasa Inggris setelah shalat subuh. Bahasa Inggris adalah bahasa internasional utama yang menjadi lingua franca semua bangsa di dunia. ${ }^{10}$ sehingga dalam hal ini tentu saja perlu bagi santri untuk mempelajari bahasa inggris agar tak ketinggalan zaman. Kegiatan pendampingan ini mendapat sambutan yang positif baik dari pihak asrama maupun santri dimana di asrama

\footnotetext{
${ }^{9}$ Richards, Jack C. \& Schmidt, Richard.(2002). Longman Dictionary of Language Teaching and Applied Linguistics. Edinburg: Pearson Education Limited., h.1

${ }^{10}$ Chaer, A. 2013. Pembinaan Bahasa Indonesia. Jakarta: PT Rineka Cipta.h.177
} 
sendiri saat ini bahasa inggris telah dimasukkan dalam jadwal belajar. Kegiatan ini memang salah satu hal yang dibutuhkan santri untuk menunjang skills dalam bahasa inggris mereka.

Kegiatan pendampingan ini dilakukan oleh santri mahasiswi STKIP Nurul Huda dan santri tingkat Aliyah yang memang tinggal di asrama tersebut dan menjadi pengurus. Berikut tabel jadwal kegiatan dan tutor dalam kegiatan ini

Tabel 1

Daftar Tutor Belajar Bahasa Inggris

\begin{tabular}{|c|c|c|c|}
\hline No & Kelas & Tutor & Lokal \\
\hline 1 & 1 Madrasah Tsanawiyyah & Nandha Martha Dinata & Unit E2 \\
\hline 2 & 2 Madrasah Tsanawiyyah & Riska Putri Susilowati & Unit E3 \\
\hline 3 & 3 Madrasah Tsanawiyyah & Feni Hania & Unit E4 \\
\hline 4 & 1 Madrasah Aliyyah & Eka Warohma & Unit E5 \\
\hline 5 & 2 Madrasah Aliyyah & Raden Ajeng Ayu & Mushola belakang \\
\hline 6 & 3 Madrasah Aliyyah & Lintang Regina Putri & Mushola depan \\
\hline
\end{tabular}

Untuk tutor mayoritas diambil dari mahasiswa, yakni untuk tutor 3 Madrasah Tsanawiyyah sampai 3 Madrasah Aliyyah. Untuk kelas 1 dan 2 Madrasah Tsanawiyyah diambil dari santri aliyyah yang memang cukup berkompeten untuk dijdikan tutor tersebut.

Tabel 2

Jawdal Belajar Bahasa Inggris

\begin{tabular}{|c|c|c|c|c|}
\hline $\mathrm{No}$ & Hari & Kelas & Materi & Metode \\
\hline 1 & Kamis & $\begin{array}{l}\text { 1-3 MA } \\
\text { 1-3 MTS }\end{array}$ & $\begin{array}{c}\text { Vocabulary dan } \\
\text { Conversation }\end{array}$ & $\begin{array}{l}\text { Hafalan dan } \\
\text { praktek }\end{array}$ \\
\hline 2 & Sabtu & $\begin{array}{l}\text { 1-3 MA } \\
\text { 1-3 MTS }\end{array}$ & $\begin{array}{l}\text { Tenses dan } \\
\text { pronunciation }\end{array}$ & $\begin{array}{l}\text { Ceramah, } \\
\text { Exercise dan } \\
\text { praktek }\end{array}$ \\
\hline
\end{tabular}

Pemberian materi masih berupa materi dasar dikarenakan ditekankan pada santri untuk dapat mempraktekkan speaking, sehingga pemilihan materi ini dianggap cukup tepat.

Dalam proses belajar ini tentulah banyak factor yang mempengaruhi proses dan hasil belajarnya. Faktor-faktor yang mempengaruhi proses dan hasil belajar meliputi tiga persoalan pokok (bagaimana belajar itu berlangsung dan prinsip-prinsip apa yang mempengaruhi proses belajar itu) dan mengenai output (hasil belajar) $^{11}$ disini kita melihat pada persoalan bagaimana proses belajar itu

${ }^{11}$ Sumadi Suryabrata, 1985. Psikologi Belajar. Yogyakarta: Universitas Gajah Mada., hal 2 
berlangsung. Secara garis besar faktor pendukung dan penghambat tersebut adalah sebagai berikut:

1. Faktor Pendukung

a. Tersedia tenaga ahli yang memadai dalam pendampingan pembelajaran bahasa Inggris dasar.

b. Antusiasme para santri yang cukup tinggi terhadap pembelajaran bahasa Inggris dasar

\section{Faktor Penghambat}

a. Keterbatasan waktu untuk pelatihan sehingga beberapa materi tidak dapat disampaikan secara detail.

b. Daya tangkap para peserta yang bervariasi, ada yang cepat namun juga ada yang lambat sehingga waktu yang digunakan kurang maksimal.

Mempelajari bahasa asing sendiri memanglah tidak mudah, sehingganya banyak kesulitan yang dihadapi terutama dalam menyimak nya para audience (santri) Menjelaskan lebih rinci bahwa ada beberapa macam kesulitan yang dialami pembelajar dalam kaitannya dengan kemampuan menyimak bahasa asing, dalam hal ini terutama bahasa Inggris, yaitu:
a) Tidak dapat memahami pengucapan (pronuonciation)
b) Tidak dapat mengontrol kecepatan berbicara penutur
c) Tidak dapat mengulangi kembali apa yang sudah didengar
d) Keterbatasan kosa kata pembelajar
e) Kesulitan/kegagalan dalam berkonsentrasi
f) Perbedaan shared knowledge yang menyebabkan perbedaan interpretasi
g) Ketidakmampuan dalam memahami tanda-tanda (signpost words)
h) Keterbatasan mengakses authentic materials dalam pembelajaran
i) Ketiadaan unsur visual yang dapat membantu pemahaman ${ }^{12}$

Selain itu, Nunan mengatakan bahwa ada empat faktor utama yang mempengaruhi penyampaian pesan dalam keterampilan menyimak (listening), yaitu:

a) Berapa banyak pembicara yang terlibat dalam suatu pembicaraan atau dialog, aksen atau dialek apa yang mereka gunakan.

b) Apa peran pendengar dalam konteks tersebut, dan respon seperti apa yang diinginkan dari keterlibatan pendengar.

c) Bagaimana ketertarikkan pendengar dengan topik yang dibicarakan.

d) Seberapa kompleks tata bahasa, dan kosa kata yang digunakan oleh pembicara.

e) Berapa banyak fasilitas penunjang yang diberikan kepada pendengar untuk memahami pesan yang disampaikan,misalnya media yang digunakan dalam

12 Machackova, Eva. (2009). Teaching Listening. Masaryk University. Brno: Brni.h.15 
membantu pendengarmemahami pesan yang disampaikan seperti gambar, diagram,atau media visual lainnya. ${ }^{13}$

Pada pendampingan pembelajaran ini, dilakukan 2 kali dalam seminggu, yakni di hari kamis dan sabtu. Di hari kamis santri diberi 25 vocabulary dan diajarkan cara membaca yang benar, kemudian hari kamis depan santri wajib menyetorkan hafalan vocabulary tersebut. Sedangkan di hari sabtu santri di bimbing belajar 16 tenses, dengan berskala. Dan terkadang juga diberi sela conversation. Penguasaan kosakata sering dipandang sebagai alat penting untuk belajar bahasa asing karena kosakata yang terbatas dalam bahasa asing akan menghambat keberhasilan komunikasi yang dilakukan ${ }^{14}$. Para pembimbing setuju bahwa hampir tidak mungkin untuk belajar bahasa tanpa menguasai katakata; bahkan komunikasi antar manusia didasarkan pada kata-kata. Demikian juga para siswa setuju bahwa akuisisi kosakata merupakan faktor utama dalam mengajar bahasa. ${ }^{15}$

Pendampingan pembelajaran bahasa Inggris dasar ini dilakukan dengan metode menghafal. Dalam Kamus Besar Bahasa Indonesia kata menghafal berasal dari kata hafal yang artinya telah masuk ingatan tentang pelajaran atau dapat mengucapkan diluar kepala tanpa melihat buku atau catatan lain. Kemudian mendapat awalan me- menjadi menghafal yang artinya adalah berusaha meresapkan ke dalam pikiran agar selalu ingat.

Disini kami memilih metode menghafal sebab sasaran kegiatan pendampingan pembelajaran Bahasa Inggris Dasar adalah santri, yang mana santri di pondok pesantren itu identik dengan hafalannya, sehingga metode inii mudah bagi santri untuk diterima.

Tujuan utama dari hafalan ini adalah sebagai langkah awal bagi santri untuk menguasai dasar bahasa Inggris, yang mana dengan menghafal banyak vocabulary dan faham tenses adalah langkah awal bagi santri untuk mendapatkan skill yang baik dalam berkomunikasi. Sebagaimana yang kita tahu bahwa perkembangan ilmu pengetahuan dan teknologi membawa dampak yang positif dan negatif. ${ }^{16}$

Menganalisa kebutuhan diartikan sebagai alat untuk mengetahui perbedaan antara apa yang telah diketahui dan apa yang mereka ingin tahu. ${ }^{17}$ jadi perlulah untuk mengetahui hal pokok yang dibutuhkan santri saat belajar, contohnya pada bahasa Inggris dasar ini. Mempelajari bahasa asing tidak terlepas lepas dari unsur penguasaan kosa kata yang luas. Kegiatan yang menguasai kosa kata menuntut kegiatan menghafalkan arti kata secara terus

\footnotetext{
13 Walter, \& J. (2004). "Teaching the use of context to infer meaning: A longitudinal survey of LI and 12 vocabulary research." Language Teaching, 37(4), 243-252.

14 Schmitt N. (2000). Vocabulary in language teaching. Cambridge: Cambridge:Cambridge University Press.h.36.

15 Nunan, D. (2003). Practical English Language Teaching. New York: Mc Graw-Hill.h.88

16 Setyawati. 2010. Analisis Kesalahan Berbahasa Indonesia. Surakarta: Yuma Pustaka.h.7

17 Nation, I. S. P. dan Macalister, J (2010). Language Curriculum Design. New York : Roudledge.h.18
} 
menerus, tanpa henti sedikit demi sedikit. Menghafal pada siswa kelas rendah sangat efektif karena memori siswa kelas rendah masih sedikit dan sangat mudah untuk menghafal kosa kata., munculnya interferensi bahasa Inggris terhadap bahasa Indonesia tidak hanya disebabkan oleh faktor gengsi, namun juga karena tuntutan akademik. ${ }^{18}$

Dalam setiap kegiatan pendampingan, seorang pendamping harus mengetahui atau peka terhadap kemampuan santri dalam bahasa Inggris dasar. Agar sekiranya kegiatan berjalan lancar dan berdampak positif. Melakukan halhal tersebut dengan baik membutuhkan pengetahuan dan keterampilan mengajar yang cukup mendalam dan luas. ${ }^{19}$

\section{Penutup}

Kegiatan pendampingan pembelajaran Bahasa Inggris ini telah diikuti oleh seluruh santri asrama putri pusat PPNH selama pelaksanaanya mengahsilkan penemuan bahwasanya santri harus di bekali kemampuan berbahasa inggris yang baik disamping pengetahuan dalam bidang agama. Program ini Alhamdulillah dapat diselenggarakan dengan lancar, meskipun belum semua peserta pendampingan menguasai materi dengan baik, hal ini dikarenakan kegiatan pendampingan ini dilakukan pertama kalinya di dalam kelas. Santri masih sering kesulitan dalam menerapkan teori-teori yang dipelajari, seperti dalam speaking. Tetapi hal ini bukanlah menjadi masalah yang besar, sebab ini baru langkah awal dalam memulai pembelajaran bahasa inggris diluar forum sekolah yang tentu saja akan memberi manfaat yang besar bagi santri dalam mempelajari keilmuan diluar agama .

\section{Daftar Pustaka}

Aitchison, Jean. (2008). Linguistics. London: Hodder Headline.

Agustina, E., Rohmah, A., \& Kuspiyah, H. (2019). Pendampingan Bimbingan Belajar Bahasa Inggris dan Bakti Sosial di Yayasan Pendidikan dan Sosial Roudlotut Thullab. Jurnal Indonesia Mengabdi, 1(1), 1-5.

Anwar, Desy, Kamus Lengkap Bahasa Indonesia, (Surabaya: Amelia, 2003), hlm. 117

Basri Hasan "Strategi Belajar Kosakata Bahasa Inggris (English Vocabulary) Mahasiswa Tbi Stain Pamekasan" jurnal Nuansa, Vol. 11 No. 2 (2014)

Brumfit (2001:35). http:// cuhyethun.blogspot.co.id/2015/08/hakikat-bahasa-inggris.html?=1 Budiarti, Any.2013. Interferensi Bahasa Indonesia ke dalam Bahasa Inggris pada Abstrak Jurnal Ilmiah.Bahasa dan Seni. (41, 1, 10-11).

18 Rakhmawati, Ani, Kundharu Saddhono, Sri Hastuti, Rio Devilito.2016. A Phenomenon of Indoglish Usage at Universities inIndonesia: Breaking Down the Motives From SociolinguisticsPerspective. Jurnal.uns.ac.id Prosiding Prasasti. (146-152).

${ }^{19}$ Cameron, L. (2001). Teaching Languages to Young Learners. UK: CUP. 
Cameron, L. (2001). Teaching Languages to Young Learners. UK: CUP.

Chaer, A. 2013. Pembinaan Bahasa Indonesia. Jakarta: PT Rineka Cipta.

Hardjono Rayner..Kamus Saku Istilah Bahasa Asing. Jakarta : Gramedia Pustaka Utama,2007

Nation, I. S. P. \& J. Macalister. (2010). Language Curriculum Design. New York:Routledge/Taylor \& Francis.

Nunan, D. (2003). Practical English Language Teaching. New York: Mc Graw-Hill.

Machackova, Eva. (2009). Teaching Listening. Masaryk University Brno: Brni.

Mulyasa 2012. Manajemen Pendidikan Karakter. Jakarta : Bumi Aksara

Mustafa, Bacharudin. Pendidikan Usia Dini. Bandung: Unpublished Book. 2007

Nana Sudjana . 2005. Dasar-dasar proses Belajar Mengajar . Sina Baru Algesindo. Bandung

Rakhmawati, Ani, Kundharu Saddhono, Sri Hastuti, Rio Devilito.2016. A Phenomenon of Indoglish Usage at Universities inIndonesia: Breaking Down the Motives From SociolinguisticsPerspective. Jurnal.uns.ac.id Prosiding Prasasti. (146-152).

Richards, Jack C. \& Schmidt, Richard.(2002). Longman dictionary of language teaching and applied linguistics. Edinburg: Pearson Education Limited.

Setyawati. 2010. Analisis Kesalahan Berbahasa Indonesia. Surakarta: Yuma Pustaka

Suryabrata, Sumadi. 1985. Paper berjudul "Psikologi Belajar, Universitas Gajah Mada". Yogyakarta.

Schmitt N. (2000). Vocabulary in language teaching. Cambridge: Cambridge:Cambridge University Press.

Walter, \& J. (2004). "Teaching the use of context to infer meaning: A longitudinal survey of LI and 12 vocabulary research." Language Teaching, 37(4), 243-252.

http://wiki.laduni.id/pesantren

https://eprints.uny.ac.id/9520/3/bab\%202-05204241004.pdf

https:/ /lister.my.id/menurut-para-ahli-pentingnya-belajar-bahasa-inggris/

https://meenta.net/pengertian-metode-praktik-menurut-ahli/

http://journal2.um.ac.id/index.php/jktp/article/download/4206/2774

http:/ / docplayer.info/30333152-Bab-ii-landasan-teori-bahasa-inggris-adalah-

bahasa-internasional-selain-yang-digunakan-untuk.html. 